Article

\title{
Exploration of Optimal Agricultural Practices and Seedling Types for Establishing Poplar Plantations
}

\section{Henrik Böhlenius * and Rolf Övergaard}

Southern Swedish Forest Research Centre, Swedish University of Agricultural Sciences, Alnarp, SE-230 53, Sweden; E-Mail: Rolf.Overgaard@slu.se

* Author to whom correspondence should be addressed; E-Mail: Henrik.Bohlenius@slu.se;

Tel.: +46-(0)40-415178; Fax: +46-(0)40-462325.

Academic Editor: Phillip G. Comeau

Received: 20 May 2015 / Accepted: 5 August 2015 / Published: 13 August 2015

\begin{abstract}
Controlling competing vegetation during early growth is one of the most important practices for the successful establishment of poplar plantations. Today, most poplar plantations in temperate regions are established on abandoned marginal agricultural land where competing vegetation is usually present during the first years after planting. Thus, the objective of this study was to examine how the growth of two kinds of poplar planting materials, un-rooted cuttings and bare-rooted seedlings was influenced by different vegetation control and soil preparation practices. Across treatments, un-rooted cuttings grew more rapidly than the bare-rooted seedlings. Our results also show that mulching with a degradable carpet or permanent polyethylene plastic increased seedling growth to a similar extent and more strongly in the cases of no treatment (in control plots). In addition, the results suggest that soil preparation in the mulched area favored seedling growth, but this effect was restricted to the first year after planting. These findings indicate that optimal practices for establishing poplar plantations on former agricultural land include planting un-rooted cuttings in prepared soil and mulching.
\end{abstract}

Keywords: Populus trichocarpa; cuttings; rooted seedlings; mulching material; plant development 


\section{Introduction}

There is increasing global interest in replacing fossil fuels with alternative renewable energy sources [1]. One method of producing large amounts of renewable energy rapidly is to plant poplars, which provide woody biomass that can be used to generate energy in several ways, including direct combustion for heating or generating electricity and ethanol production [2]. Thus, poplar plantations are being established in substantial areas in temperate regions of the world, mainly on abandoned agricultural land [3-5]. At these sites competing vegetation is present and/or establishes at the time of planting or during the first following years, which is a critical period for the success of poplar plantations because Populus spp. are highly sensitive to competition [5-7]. Moreover, at these sites soil preparation will destroy the current vegetation cover but an important seedbank remains, which could result in a fast re-establishment of competing vegetation. In the Nordic area, the critical establishment period for conifers is up to 3-4 years after planting [8,9], and vegetation control should also be maintained in poplar plantations for up to 3-4 years to maximize growth [10]. This can be done chemically, mechanically, by tilling or harrowing, or by mulching with wood chips, plastic carpets, or other materials [10,11]. If permanent inflexible mulching material is used, it should be removed after three or four years, otherwise growth of the seedlings may be hindered and/or they may be damaged due to physical restriction. This demands additional work after the critical vegetation control period, so use of a degradable mulching material might be preferable. However, the relative effects of using a permanent or degradable mulching material on poplar growth are largely unknown.

A further consideration is that poplars can initiate adventitious roots from their stems, so stem cuttings can be used as transplants for establishing poplar plantations [12-14], but containerized or bare-rooted plants are also used. Bare-rooted plants differ from cuttings in several respects, as they have developed roots and substantial above-ground parts, while cuttings have no roots and very small above-ground parts. These differences could significantly influence the establishment and growth of transplants during the first few years after planting. Root growth is favored in soils with high temperature and moisture $[15,16]$, and the removal of competing vegetation by mechanical treatments or covering the soil with mulching material can alter these parameters $[11,17,18]$. However, high soil temperature and moisture could be more important for cuttings than for rooted plants of hardwood species, as cuttings first need to develop roots to reach soil water. Thus, growth responses to vegetation control methods may depend on the kind of planting material used. Additional soil preparation might further improve the microclimate for the transplants, as soil preparation increases temperature [19,20] and soil moisture [21], but in combination with different mulches the effects of soil preparation might be different.

Thus, in the study presented here we investigated effects of several possible vegetation control practices on the establishment and early growth of poplar cuttings and rooted plants on abandoned agricultural land in Sweden. Specific objectives were to compare effects of mechanical weed control and mulching with a degradable or permanent plastic, with and without soil preparation, and how growth was influenced by the two plant types. Experimental plots treated in these manners were monitored during the first two years after planting poplar. 


\section{Materials and Methods}

\subsection{The Experimental Site and Vegetation Data}

The experiment was situated in Vaxtorp $\left(56^{\circ} 25^{\prime} \mathrm{N}, 13^{\circ} 05^{\prime} \mathrm{E}, 40 \mathrm{~m}\right.$ above sea level $), 12 \mathrm{~km}$ from the west coast in southern Sweden. The site is a former forest plant nursery. Vegetation biomass and the percentage of vegetation cover were determined in a randomly placed $50 \times 50 \mathrm{~cm}$ quadrant in the untreated plots two years after planting. The vegetation inside each quadrant was harvested, roots were washed and oven-dried at $70{ }^{\circ} \mathrm{C}$ for 48 hours before being weighed. Two years after planting, 100\% of the soil surface was covered by competing vegetation with a biomass of $23.3 \pm 2.6 \mathrm{~g} \mathrm{~m}^{-2}$ and the height of the vegetation was approximately $15-25 \mathrm{~cm}$. The competing vegetation consisted mainly of the grass species Nardus stricta L. The experimental site was fenced to exclude browsing. The annual precipitation is about $1000 \mathrm{~mm}$ and the mean annual temperature about $8{ }^{\circ} \mathrm{C}$ [22]. The soil type is a well-drained sandy loam, $\mathrm{pH} 5.8$, total nitrogen $0.12 \%$, and available $\mathrm{P} 13.6 \mathrm{mg}$ per $100 \mathrm{~g}$ soil.

\subsection{Experimental Design, Vegetation Control Method, and Plant Material}

Two types of mulching carpets were used, both in $100 \mathrm{~cm}$ strips: Mypex (WaterBoys AB, Alvesta, Sweden) and Viaweed U (Viacon Ab, Lidköping, Sweden). Mypex is a permanent woven inflexible polypropylene plastic carpet that cannot be broken by growing plants and allows precipitation to penetrate but prevents soil moisture from evaporating. It can be degraded by UV light, but is guaranteed to last at least five years, and in many cases the plastic remains intact for 15 years. Viaweed $U$ is a flexible polypropylene fabric that can be broken by a growing plant, but otherwise has similar characteristics to Mypex except that it is only guaranteed to resist UV light for 2-3 years. The experiment was established at the beginning of June 2012 and ended in October 2013. Three blocks were established, each containing six plots that were randomly assigned to different vegetation control treatments. All treatments were applied in $1 \mathrm{~m}$ wide strips, with $2 \mathrm{~m}$ spacing between treatments. The treatments consisted of: (1) mechanical vegetation control twice a year with a tiller (Honda F220, Honda Motor Co., Inc, Alpharetta, GA, US) disturbing the soil to a depth of $10 \mathrm{~cm}$ (designated Mech); (2) and (3) mulching with Mypex (designated Perm-plast) and Viaweed (designated Deg-carp), respectively, in both cases directly anchored on top of existing vegetation; (4) and (5) mulching as in treatments (2) and (3), respectively, but after soil preparation ( $\mathrm{sp}$ ) by plowing (preparing the upper $30 \mathrm{~cm}$ of the soil), followed by harrowing with a disc harrow (preparing the upper $15 \mathrm{~cm}$ of the soil) (designated Perm-plast sp and Deg-carp sp, respectively). In plots with treatment Mech, the soil was first treated with plowing and harrowing. In the final control treatment, no site preparation or mulching was applied (designated Untreat). Before planting, the un-rooted cuttings were soaked in water for 24 hours. In each of the six plots in each block, eight plants of each type were planted in groups in the middle of the $1 \mathrm{~m}$ strips with $2 \times 2 \mathrm{~m}$ spacing between plants. The groups of different planting material were manually planted in each of the plots of $4 \times 8 \mathrm{~m}$ at a transplanting depth of $20 \mathrm{~cm}$ to $25 \mathrm{~cm}$.

Hybrid poplar (P. trichocarpa $\times$ P. maximowiczii) clone OP42 was selected for the study due to its commercial availability, good rooting capability, and performance. Two planting materials were used: bare-rooted plants (length $55 \mathrm{~cm}$, root-collar diameter $8-10 \mathrm{~mm}$ ) and un-rooted cuttings (length $30 \mathrm{~cm}$, diameter 10-13 mm). The rooted cuttings were purchased from Svenska skogsplantor, Hallsberg, 
Sweden, and the dormant cutting material was harvested in winter and stored in a cold room at $+4{ }^{\circ} \mathrm{C}$ until the time of planting. These materials are hereafter respectively referred to as rooted plants and un-rooted cuttings when discussing the plant types, and rooted seedlings and seedlings from un-rooted cuttings when discussing growth.

\subsection{Height Measurements and Collection of Biomass}

The height growth of eight trees in each plot was measured every second week from 6 June during the first year after planting and after the growth period of the second year. At the end of the first growth period (September), two plants per plot and planting type were harvested, then separated into leaf, stem, and root parts, which were dried at $70{ }^{\circ} \mathrm{C}$ for 48 hours (after washing the roots), then weighed.

\subsection{Statistical Analysis}

To test effects of the treatments on the measured variables, the general linear model (GLM) and mixed model procedures, as implemented in SAS software (SAS Institute Inc., Cary, NC, USA), were used. Vegetation control treatment was set as the main factor and block as a random factor. To evaluate growth per day during the first year after planting, a repeated measures design was used. Tukey's test, with significance set at the 5\% level, was used to determine significant differences [23]. All tested variables were examined for distribution, residuals, and homoscedasticity using the UNIVARIATE procedure and transformed when necessary to obtain an even variable distribution. The response factor $y$ was transformed as follows: $\log (1+y)$ for root and stem biomass of rooted plants; rank y for cutting stem biomass allocation; $y^{2}$ for cutting leaf biomass allocation; $1 / y$ for height growth of rooted plants at year one [24]. When none of these transformations produced a satisfactory variable distribution, the Wilcoxon rank method was used for analysis [25]. Results presented in figures are original data.

\section{Results}

\subsection{Height Growth and Seedling Mortality}

Mortality rates of the transplants were zero for all treatment and planting material combinations, i.e., all of the transplants survived for the whole two-year study period.

After both years, seedlings of both types had grown more in height under the mulching treatments with either the degradable plastic carpet (Deg-carp) or polypropylene plastic (Perm-plast), with or without prior soil preparation (Deg-carp sp and Perm-plast sp), than in control (Untreat) plots (Figure 1). The mechanical vegetation control treatment (Mech) also resulted in greater height growth in both years for rooted plants and in the second year for seedlings from un-rooted cuttings. The Deg-carp sp and Perm-plast sp treatments resulted in greater height growth of un-rooted cuttings than the Mech treatment during the first year, but there was no significant difference in this respect at the end of the second year (Figure 1A,C). Two years after planting, rooted seedlings were taller under the Deg-carp sp and Perm-plast sp treatments than under the Mech treatment (Figure 1D). For both planting types and in both years, Deg-carp and Perm-plast mulch, with or without soil preparation, increased height growth to a similar extent. Across treatments, seedlings from un-rooted cuttings grew significantly more in height than rooted plants (first year $p=0.001$, second year $p=0.042$ ), but no significant within-treatment differences 
in their height growth were detected. Soil preparation prior to mulching tended to increase height growth during the first year (Perm-plast $p=0.097$, Deg-carp $p=0.085)$, but there was no indication of such an effect after the second year.
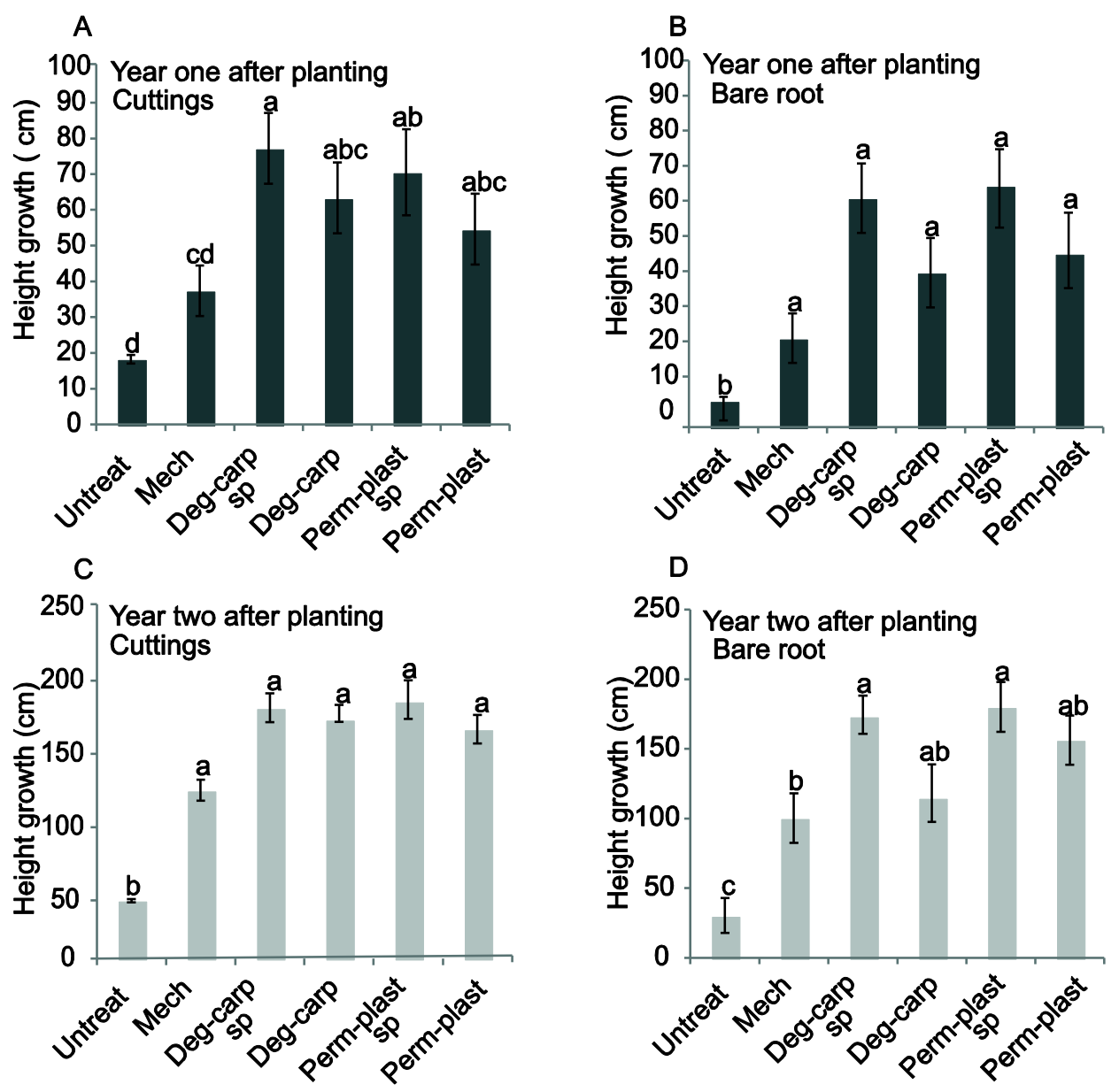

Figure 1. Height growth the first and second years after planting. Height growth of seedlings from un-rooted cuttings (A and $\mathbf{C})$ and rooted plants (B and $\mathbf{D})$, one year (A and $\mathbf{B})$ and two years (B and D) after planting under each of the treatments: control (Untreat), mechanical vegetation control (Mech), mulching without soil preparation using degradable carpet (Deg-carp) or permanent polypropylene plastic (Perm-plast), and with soil preparation (Perm-plast sp and Deg-carp sp). Values with the same letter are not significantly different at the $p=0.05$ level: means $(n=3)$, error bars indicate standard errors.

\subsection{Growth Rates in the Early Phase of Establishment}

No height growth of seedlings from rooted plants or un-rooted cuttings was detected in untreated control plots after 2 August (Figure 2A), but seedlings in other plots continued to grow (Figure 2B-F). In addition, seedling growth terminated earlier in Mech plots (Figure 2B) than in mulched plots (Figure 2C-F). Seedlings from un-rooted cuttings grew more rapidly than the rooted plants initially, especially in the Untreat, Mech, and Deg-carp plots (Figure 2A, B, D). However, under the Perm-plast, Perm-plast sp, and Deg-carp sp treatments there were no significant differences in growth rate between the planting material types. Under the Untreat and Deg-carp treatments, seedlings from un-rooted 
cuttings grew more rapidly than rooted plants until the beginning of August (Figure 2A,D), while seedlings grown in Mech plots only grew more rapidly initially (Figure 2B).
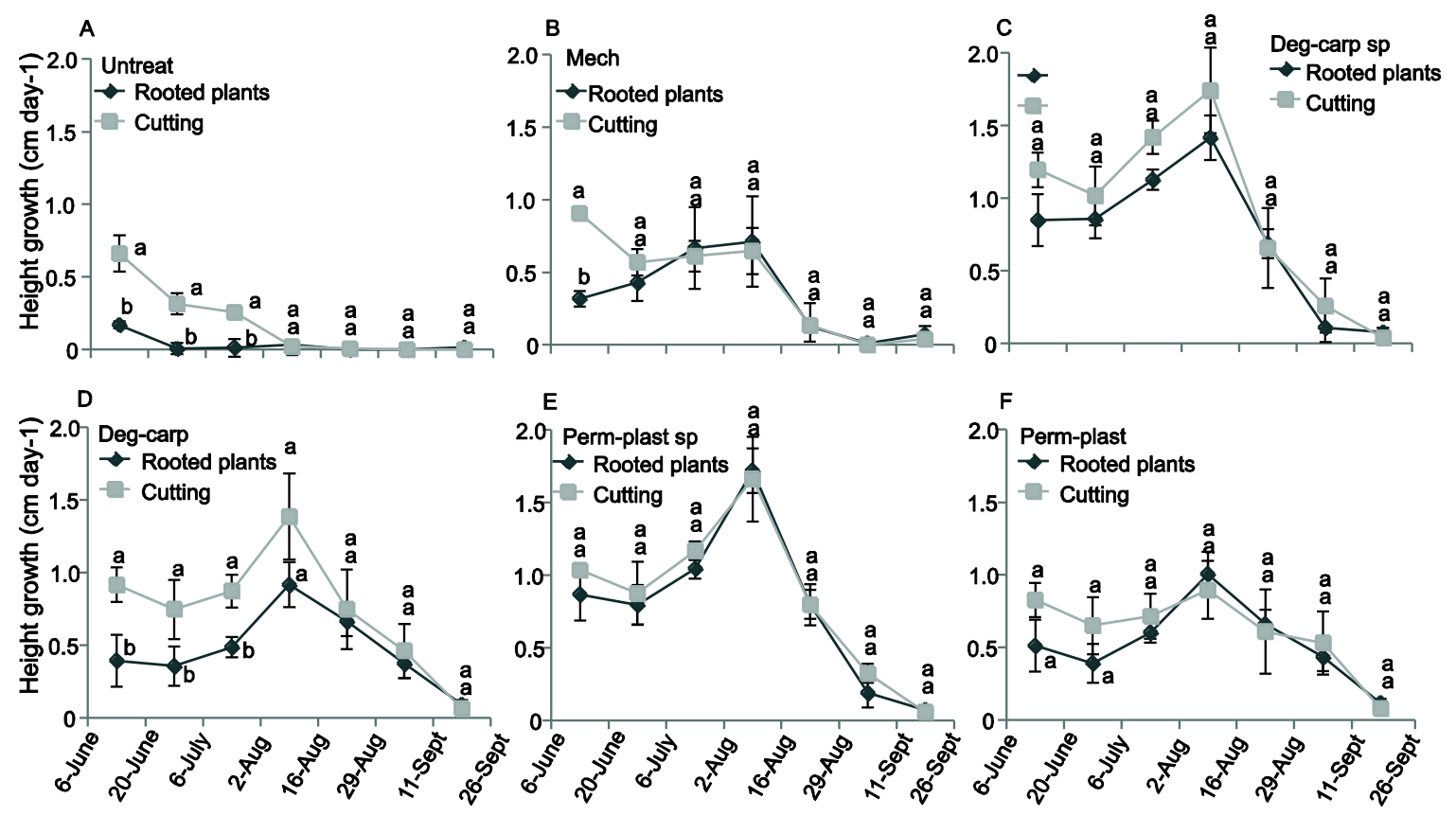

Figure 2. Height growth rate during the first year after planting. Height growth rate during the first year, in cm per day, for rooted cuttings and un-rooted plants grown under each of the treatments: control (Untreat), mechanical vegetation control (Mech), mulching without soil preparation using degradable carpet (Deg-carp) or permanent polypropylene plastic (Perm-plast), and with soil preparation (Perm-plast sp and Deg-carp sp). Values with the same letter are not significantly different at the $p=0.05$ level: means $(n=3)$, error bars indicate standard errors.

\subsection{Biomass Production}

For seedlings from un-rooted cuttings, mulching had a positive effect on leaf biomass compared with the Mech and control treatments, under which their biomasses were similar (Figure 3A). Seedlings grown under the Deg-carp sp and Perm-plast treatments had higher stem biomasses than counterparts grown under the control and Mech treatments that showed similar values. Deg-carp and Perm-plast sp treatments increased seedling stem biomass more than the control treatment, and there were strong tendencies towards significant differences between the Deg-carp and Mech treatments $(p=0.069)$, and between the Perm-plast sp and Mech treatments $(p=0.055)$ (Figure 3B). Root biomass of the seedlings from un-rooted cuttings was similar under all treatments, apart from being higher in Deg-carp sp plots than in control, Mech, and Perm-plast sp plots (Figure 3C).

For rooted seedlings, leaf biomass was higher in Deg-carp sp, Perm-plast sp, and Perm-plast plots than in Untreat and Mech plots (Figure 3D). Seedlings grown in Perm-plast and Perm-plast sp plots had higher stem biomass than those grown in Untreat and Mech plots, while rooted seedlings grown in Deg-carp and Deg-carp sp plots had higher biomass than those grown in control plots (Figure 3E). Rooted seedlings grown under the Mech treatment also had higher stem biomass than those in control 
plots, and there was a strong tendency toward a difference in their stem biomass between the Deg-carp sp and Mech treatments, with $p=0.079$. Seedlings grown in Perm-plast, Perm-plast sp, and Deg-carp sp plots had higher root biomass than those in Mech and control plots, and those grown in Deg-carp and Mech plots had higher root biomass than rooted seedlings in the Untreat plots.
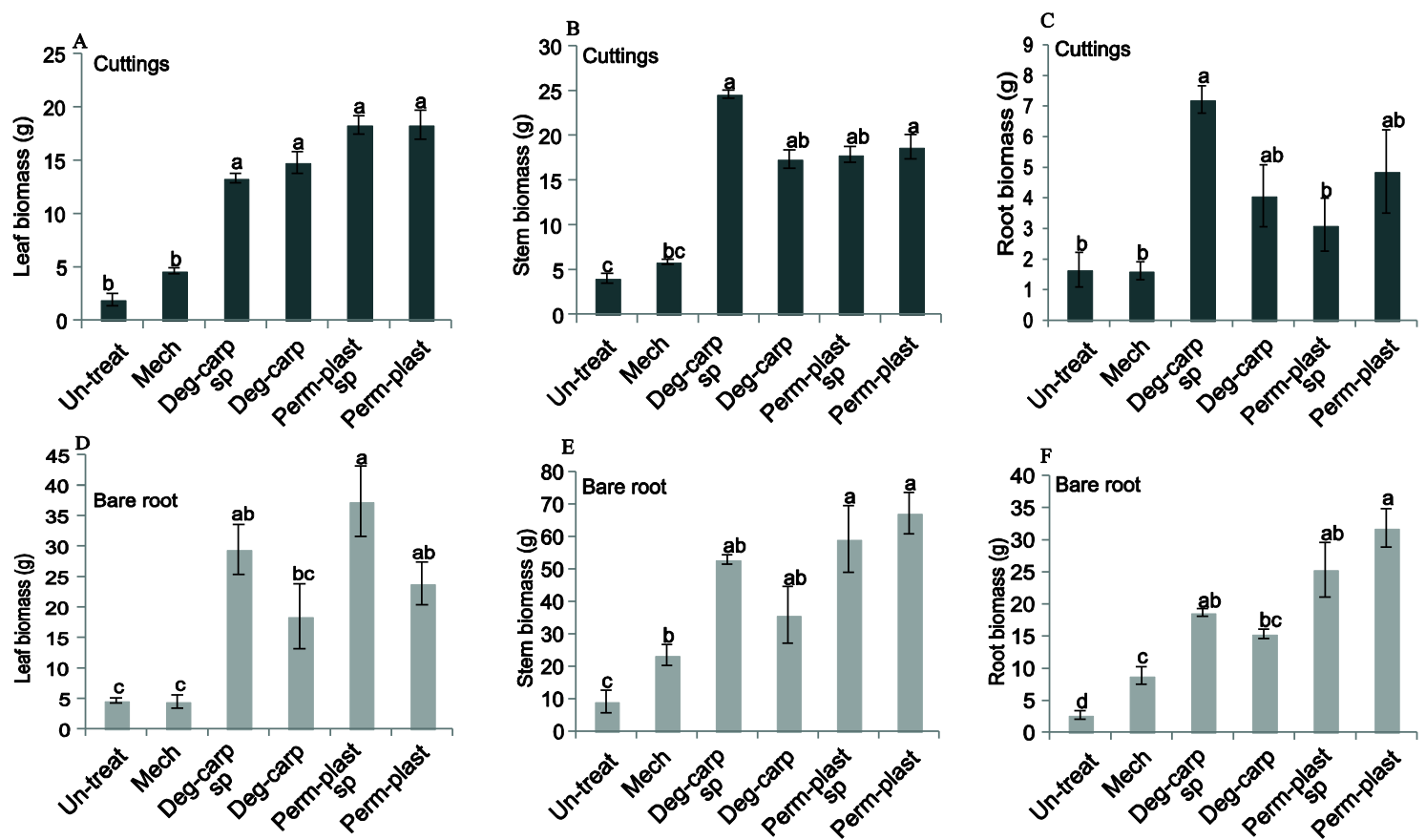

Figure 3. Biomass production after the first year of growth. Production after the first year, of un-rooted cuttings $(\mathbf{A}-\mathbf{C})$ and rooted plants $(\mathbf{D}-\mathbf{F})$ of root biomass $(\mathbf{A}$ and $\mathbf{D})$, stem (B and $\mathbf{E})$, and leaf ( $\mathbf{C}$ and $\mathbf{F})$ biomass under each of the treatments: control (Untreat), mechanical vegetation control (Mech), mulching without soil preparation using degradable carpet (Deg-carp) or permanent polypropylene plastic (Perm-plast), and with soil preparation (Perm-plast sp and Deg-carp sp). Values with the same letter are not significantly different at the $p=0.05$ level: means $(n=3)$, error bars indicate standard errors.

\subsection{Biomass Allocation}

No treatment effects on biomass allocation to stems and leaves were detected in either of the planting materials, except that leaves of rooted seedlings grown in Mech plots had lower proportions of leaf and stem biomass than those in control plots (Figure 4). Root biomass proportions were significantly higher in seedlings from un-rooted cuttings in Untreat plots than in those in Perm-plast and Dec-carp plots, while they were similar in those grown in Untreat, Mech, and Dech-carp sp plots. For rooted seedlings, root biomass proportions were higher in Perm-plast plots than in Deg-carp sp and control plots, and higher in Deg-carp, Mech, and Perm-plast plots than in Untreat plots. 

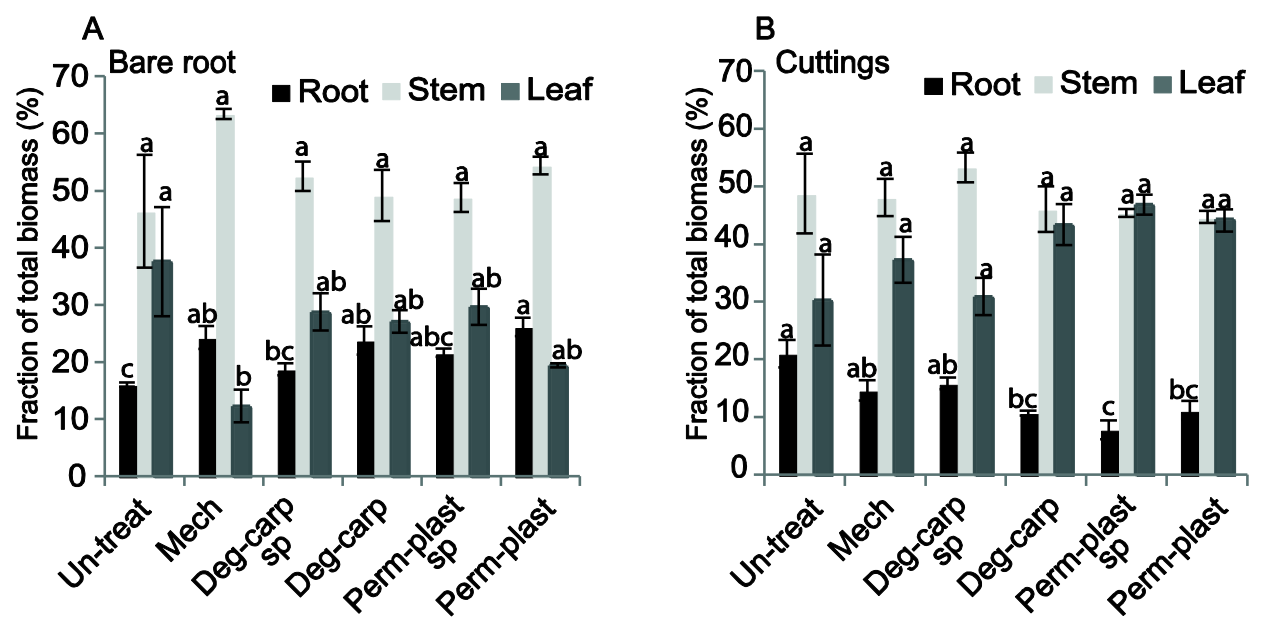

Figure 4. Biomass allocation. Biomass allocation (\%) to roots, stems, and leaves in rooted plants (A) and un-rooted cuttings (B) at the end of the first growing period under each of the treatments: control (Untreat), mechanical vegetation control (Mech), mulching without soil preparation using degradable carpet (Deg-carp) or permanent polypropylene plastic (Perm-plast), and with soil preparation (Perm-plast sp. and Deg-carp sp.). Values with the same letter (for the same planting material and for the same vegetal tissue) are not significantly different at the $p=0.05$ level: means $(n=3)$, error bars indicate standard errors.

\section{Discussion}

We investigated the effects of several vegetation control treatments, with and without soil preparation, on the establishment of two types of poplar planting materials, un-rooted cuttings and rooted plants, on abandoned agricultural land. Two main findings are that the un-rooted cuttings grew more strongly in height than the rooted plants across treatments, and that there were minor differences in growth (in either planting material) between treatments with the two different mulching carpets. Use of both mulching carpets increased plant height and leaf and stem biomass to similar extents compared to the control treatment. Our results are consistent with previous findings that the poplar has low tolerance for competing vegetation [10,26]. Generally, they also suggest that mulching is as effective as mechanical vegetation control (Figure 1A-D). However, we found that prior soil preparation tended to significantly improve the height growth of plants in mulched plots (of both types) after the second year of growth (Perm-plast $p=0.097$ and Deg-carp $p=0.085$ ). Thus, these results are only partially consistent with a recent report that mulching increases plant growth more than manual vegetation control of similar intensity [18]. In contrast to height growth, plantbiomasses were different between the mechnical vegetation control and mulching treatments (Figure 3). However, in other locations, competing vegetation could be more abundant and, therefore, differences between vegetation control treatments could be larger due to competition for below-ground resources such as water and nutrients.

Changes in the growth of poplars are often associated with changes in leaf development, as it is one of the key growth determinants [27]. Accordingly, leaf biomass of un-rooted seedlings was higher in mulched plots, with and without site preparation, than in other plots (Figure 3A,D). However, it did not differ between plants in Mech plots and untreated control plots. Thus, vegetation control by mulching may enable hybrid poplars to invest biomass in leaf production, and the observed increases in leaf 
development could be due to shifts in biomass allocation from root to leaves induced when nitrogen availability is increased as a result of vegetation control [28]. This should result in a reduction in the allocation of biomass to roots and an increased allocation to leaves when vegetation control is applied.

We found reductions in biomass allocation to roots of seedlings from un-rooted cuttings grown in Deg-carp, Perm-plast, and perm-plast sp plots (Figure 4B), but not among rooted plants (Figure 4A). This difference is probably due to the latter's large root biomass at the time of planting, which reduces the influence of newly formed roots and, thus, differences in root biomass between the treatments could not be found. Our study therefore partially supports previous findings that mulching has no effect on [29] or increases [28,30-32] biomass allocation to roots. Mulching with polyethylene plastic (or other material) can create a soil environment that enhances plant growth by both increasing soil temperatures [11] and soil moisture contents [18,33,34]. Increases in soil temperature might enhance nutrient mineralization and, thus, nutrient availability [35]. This suggests that vegetation control by mulching or mechanical treatment promotes the growth of planted material not only through increasing the abundance of available nutrients, but also by increasing the water content, which facilitates nutrient uptake, since the delivery of nutrients by mass flow is hampered in dry soils [36]. This hypothesis is corroborated by results of a previous experiment in which mulching (using the same Perm-plast material as in this experiment) increased nitrogen content in poplar plants, and the increases were correlated with the mulched area [18]. The observed growth differences between plants grown in mechanical and mulching plots could be a consequence of different processes that together influence plant growth. There are two major mechanisms for plant competition: resource competition and interference [37]. In our study, interference could have played a role for transplanted cuttings in untreated plots while bare-rooted plants were most likely not affected due to their high initial height at planting. It is therefore more likely that competition for resources was important in this study and that the mechanical and mulching treatments might have influenced below-ground resources differently. In general, soil resources reach the root by three different processes: mass flow of water and nutrients, diffusion, and interception [38] that plays a minor role [36]. The supply of the three major nutrients $(\mathrm{N}, \mathrm{P}$, and $\mathrm{K}$ ) is commonly dependent on diffusion and mass flow working together [39], but it is difficult if not impossible to distinguish between them [38]. Neighboring roots could reduce nutrient uptake when depletion zones overlap [40] and, therefore, even a small amount of competing vegetation could result in large growth differences. If mulching with Deg-carp and Perm-plast increases both soil moisture and nutrient availability, this could result in dramatic growth differences between untreated plots and mulched plots. However, we could identify a dramatic growth difference between untreated plots and mulched plots (Figures 1 and 3) and also increased growth between mechanical and mulch-treated plots. Interestingly, in another experiment at the same site, the same Deg-carp treatment increased soil moisture more than manual vegetation control while temperatures were unaffected [18].

In the present study, we detected no mortality of the planted material under any treatment, probably due to the low amount of competing vegetation that established during the two years of monitored growth. However, with other poplar genotypes, and/or at other sites with higher competition from vegetation, different vegetation control methods or materials could have differing effects on plant growth and mortality [11], and differences in the planted material (un-rooted cuttings and rooted plants) could also presumably influence growth parameters. Under low soil moisture conditions, mulching can be a 
valuable vegetation control option because it increases plant survival rates $[41,42]$ and, under such conditions, bare-rooted seedlings might perform better than cuttings. However, the soil at the experimental site is a well-drained, quite dry, sandy loam, and growth of the seedlings from both plant materials under mulching treatments was similar. We could infer that the higher growth rate of un-rooted cuttings presumably originates from faster growth at the beginning of the vegetation period (Figure 2). In accordance with previous findings [18], seedlings of both planting materials terminated growth earlier in plots with no vegetation control than in plots with vegetation control (Figure 2).

Poplars can initiate adventitious roots from their stems, so cuttings can be planted to establish plantations [12-14]. The initially high growth of un-rooted cuttings is surprising, since they need to develop new roots to access soil water and nutrients, while bare-rooted plants already have a root system at planting and thus should be able to take up soil water and nutrients more rapidly. However, newly planted bare-rooted plants could have poor root-soil contacts and/or root confinement [43]. If bare-rooted plants are able to regenerate new roots, water stress is reduced, allowing seedlings to resume normal growth [43]. Thus, the development of new roots is presumably needed to create contact with the soil to facilitate water and nutrient uptake. If the soil conditions are appropriate, poplar roots grow rapidly and they can develop root systems more than $1 \mathrm{~m}$ deep during the first year [44], and the buried portion of the stem can produce new roots while the nursery roots that remain after lifting also may regenerate [10]. However, in our experiment both un-rooted cuttings and bare-rooted plants may solely use newly developed roots during their establishment. As the bare-rooted plants have large above-ground parts to support, this might explain the initial growth differences between rooted and un-rooted transplants.

There are several advantages to using un-rooted cuttings instead of rooted plants: Notably, they are less expensive planting material, easier to store until planting, and the procedure for planting them is simpler and easy to mechanize. However, there are soil factors (rocks and compaction) that could complicate the planting of both plant types. Differences in plant morphology between cuttings and bare-rooted plants might influence the planting process (cuttings have no roots and bare-rooted plants have large roots). In the case of rocks in the soil, creating a hole only for the cutting could easily be performed. For bare-rooted plants it could be more challenging to find a planting site where the transplant could be planted to the right depth due to the large root. This would also be the case if cuttings or bare-rooted plants would be planted in compact soils.

However, a shoot growing from an un-rooted cutting is more sensitive to damage by rodents and other browsers, as they have smaller stem diameters than rooted plants (which generally have $c a .10 \mathrm{~mm}$ diameters at the time of planting). On the other hand, rooted seedlings of the kind used here, about $50 \mathrm{~cm}$ tall at the time of planting, have a large above-ground biomass that requires significant amounts of water.

There are several advantages and several disadvantages of using mulching instead of mechanical vegetation control. Notably, despite continual observation, plots subjected to mechanical vegetation control are not always $100 \%$ free from vegetation, while the mulched areas always were in this experiment. This could further increase growth differences between mulched and mechanically controlled plants. Thus, the use of permanent or degradable mulching material during the first years of poplar establishment could be extremely valuable, as competing vegetation is always controlled, with no need to monitor the growth of competing vegetation. However, at some point the Deg-carp will cease to provide vegetation control while the Perm-plast will continue to control vegetation. This will probably 
occur after the critical vegetation control period is over [10] and will probably not negatively influence growth if Deg-carp would be used instead of Perm-plast. In poplar plantations established over large areas it could be difficult to maintain optimal growth conditions. In such cases, mulching could be a particularly useful vegetation control method. However, if permanent polypropylene plastic is used for mulching, it must be removed at some point or seedling growth will be restricted. Our results suggest that a degradable carpet is as effective as permanent mulch for providing good establishment conditions, and this mulching material does not have to be removed. It should be noted that it is important to anchor the mulching carpet properly, otherwise wind may damage both the mulch carpet and growing seedlings. There may also be risks of increased plant damage by rodents under the mulch carpets.

\section{Conclusions}

Our results demonstrate that vegetation control during the first two years after planting strongly promotes the establishment and growth of hybrid poplars. Compared to plants grown with no vegetation control, mechanical vegetation control increased growth by $100 \%$ and mulching by $200 \%$. Both mulching materials tested increased growth to a similar extent, while preparing the soil before mulching only had marginal effects. In Sweden today, poplar plantations are established by planting rooted seedlings. Our results indicate that establishing poplar plantations with un-rooted cuttings is equally effective. This finding could change current practices for establishing poplar plantations, as using un-rooted cuttings as transplants is less time-consuming and less expensive, thus it could be financially beneficial. However, a clear understanding of the actual economic benefits of mulching will require a long-term assessment of growth trends at sites with different characteristics.

\section{Acknowledgments}

The authors thank Urban Nilsson and Björn Sundberg for comments and suggestions at an early stage of the manuscript. The authors gratefully acknowledge the field assistance provided by Ulf Johansson at Tönnersjö Forest Research Station. This project was funded by the Swedish research program, Trees and Crops for the Future (TC4F), a Vinnova project, and Bio4energy a Strategic Research Environment appointed by the Swedish government.

\section{Author Contributions}

Henrik Böhlenius conceived and designed the experiments; Henrik Böhlenius performed the experiments; Rolf Övergaard analyzed the data; Henrik Böhlenius wrote the paper together with Rolf Övergaard.

\section{Conflicts of Interest}

The authors declare no conflict of interest.

\section{References}

1. Ma, Q.; Lebedys, A. Poplars and Willows, Trees for Society and the Environment; Isebrands, J.G., Richardson, J., Eds.; CABI: Oxfordshire, UK, 2014; pp. 573-574. 
2. National Research Council of Canada Research Press. Poplar Culture in North America; Dickmann, D.I., Isebrands, J.G., Eckenwalder, J.E., Richardson, J., Eds.; National Research Council of Canada Research Press: Ottawa, Canada, 2001.

3. Christersson, L. Poplar plantations for paper and energy in the south of Sweden. Biomass Bioenergy 2008, 32, 997-1000.

4. Christersson, L. Wood production potential in poplar plantations in Sweden. Biomass Bioenergy 2010, 34, 1289-1299.

5. Tullus, A.; Rytter, L.; Tullus, T.; Weih, M.; Tullus, H. Short-rotation forestry with hybrid aspen (Populus tremula L. $\times$ P. tremuloides Michx.) in northern Europe. Scand. J. For. Res. 2011, 27, 10-29.

6. Coll, L.M.; Delagrange, C.; Berninger, S.F. Growth, allocation and leaf gas exchanges of hybrid poplar plants in their establishment phase on previously forested sites: Effect of different vegetation management techniques. Ann. For. Sci. 2007, 64, 275-285.

7. Otto, S.; Loddo, D.; Zanin, G. Weed-poplar competition dynamics and yield loss in Italian short-rotation forestry. Weed Res. 2010, 50, 153-162.

8. Wagner, R.G.; Mohammed, G.H.; Noland, T.L. Critical period of interspecific competition for northern conifers associated with herbaceous vegetation. Can. J. For. Res. 1999, 29, 890-897.

9. Wagner, R.G.; Noland, T.L.; Mohammed, G.H. Timing and duration of herbaceous vegetation control around four northern coniferous species. For. Sci. 1996, 26, 39-52.

10. Hansen, E.A.; Netzer, D.; Toldsted, D.N. Guideline for Establishing Poplar Plantations in the North-West U.S.; Deptartment of Agriculture, Forest Service, North Central Forest Experiment Station: St. Paul, MN, USA, 1993.

11. Green, D.S.; Kruger, E.L.; Stanosz, G.R. Effects of polyethylene mulch in a short-rotation, poplar plantation vary with weed-control strategies, site quality and clone. For. Ecol. Manag. 2003, 173, 251-260.

12. DeBell, D.S.; Harrington, C.A. Productivity of Populus in monoclonal and polyclonal blocks at three spacings. Can. J. For. Res. 1997, 27, 978-985.

13. Hartmann, H.T.; Kester, D.E. Plant Propagation: Principles and Practices; Prentice-Hall: Englewood Cliffs, NJ, USA, 1975; p. 609.

14. Hofmann-Schielle, C.; Jug, A.; Makeschin, F.; Rehfuess, K.E. Short-rotation plantations of balsam poplars, aspen and willows on former arable land in the federal republic of Germany. I. Site-Growth relationships. For. Ecol. Manag. 1999, 121, 41-55.

15. Tryon, P.R.; Chapin, F.S., III, Temperature control over root growth and root biomass in taiga forest trees. Can. J. For. Res. 1983, 13, 827-833.

16. Lopushinsky, W.; Max, T.A. Effect of soil temperature on root and shoot growth and on budburst timing in conifer seedling transplants. New For. 1990, 4, 107-124.

17. Johansson, K.; Örlander, G.; Nilsson, U. Effects of mulching and insecticides on establishment and growth of Norway spruce. Can. J. For. Res. 2006, 36, 2377-2385.

18. Böhlenius, H.; Övergaard, R. Growth response of hybrid poplars to different types and levels of vegetation control. Scand. J. For. Res. 2015, 1-19, doi:10.1080/02827581.2015.1034768.

19. Kubin, E.; Kemppainen, L. Effect of soil preparation of boreal spruce forest on air and soil temperature conditions in forest regeneration areas. Acta For. Fenn. 1994, 244, 1-56. 
20. Nilsson, U.; Örlander, G. Vegetation management on grass-dominated clearcuts planted with Norway spruce in southern Sweden. Can. J. For. Res. 1999, 29, 1015-1026.

21. Nilsson, U.; Örlander, G. Effects of regeneration methods on drought damage to newly planted Norway spruce seedlings. Can. J. For. Res. 1995, 25, 790-802.

22. SMHI (Swedish Meteorological and Hydrological Institute). Available online: http://www.smhi. se/klimatdata/ (accessed on 2 October 2014).

23. Quinn, G.P., Keough, M.J. Experimental Design and Data Analyses for Biologists; Cambridge University Press: Cambridge, UK, 2002.

24. Transformations, an Introduction. Available online: http://fmwww.bc.edu/repec/bocode/t/ transint.html (accessed on 10 July 2015).

25. Wonnacott, W.; Wonnacott, T. Introductory Statistics; Wiley: New York, NY, USA, 1985.

26. Bergstedt, A.E. Dyrkning Af Poppel (How to Grow Poplars); Statens forstlige Forsøgsvæsen: Genotryck, Denmark, 1981; p. 106.

27. Pellis, A.; Laureysens, I.; Ceulemans, R. Growth and production of a short rotation coppice culture of poplar I. Clonal differences in leaf characteristics in relation to biomass production. Biomass Bioenergy 2004, 27, 9-19.

28. Cooke, J.E.K.; Martin, T.A.; Davis, J.M. Short-term physiological and developmental responses to nitrogen availability in hybrid poplar. New Phytol. 2005, 167, 41-52.

29. Domenicano, S.; Coll, L.; Messier, C.; Berninger, F. Nitrogen forms affect root structure and water uptake in the hybrid poplar. New For. 2011, 42, 347-362.

30. Albaugh, T.J.; Allen, H.L.; Dougherty, P.M.; Kress, L.W.; King, J.S. Leaf area and above- and belowground growth responses of loblolly pine to nutrient and water additions. For. Sci. 1998, 44, 317-328.

31. Beets, P.N.; Whitehead, D. Carbon partitioning in Pinus radiata stands in relation to foliage nitrogen status. Tree Physiol. 1996, 16, 131-138.

32. Coleman, M.D.; Friend, A.L.; Kern, C.C. Carbon allocation and nitrogen acquisition in a developing Populus deltoides plantation. Tree Physiol. 2004, 24, 1347-1357.

33. Parfitt, R.I.; Stott, K.G. Effects of mulch covers and herbicides on the establishment, growth and nutrition of poplar and willow cuttings. Asp. Appl. Biol. 1984, 5, 305-313.

34. Ramakrishna, A.; Tam, H.M.; Wani, S.P.; Long, T.D. Effect of mulch on soil temperature, moisture, weed infestation and yield of groundnut in northern Vietnam. Field Crops Res. 2006, 95, 115-125.

35. Stanford, G.; Frere, M.H.; Schwaninger, D.H. Temperature coefficient of soil nitrogen mineralization. Soil Sci. 1973, 115, 321-323.

36. Marschner, H. Mineral Nutrition of Higher Plants, 2nd ed.; Academic Press : London, UK, 1995.

37. Tilman D. Mechanisms of plant competition for nutrients: The elements of a predictive theory of plant competition. In Perspectives on Plant Competition; Grace, J.B., Tilman, D., Eds.; Academic Press: San Diego, CA, USA, 1990; pp. 117-141.

38. Casper, B.; Jackson, B. Plant competition underground. Ann. Rev. Ecol. Syst. 1997, 28, 545-570.

39. Nye, P.H.; Tinker, P. Solute Movement in the Soil-root System; University of California Press: Berkeley, CA, USA, 1977.

40. Baldwin, J.P. Competition for plant nutrients in soil: A theoretical approach. J. Agric. Sci. 1976, $87,341-356$. 
41. Debyle, N.V. Black polyethylene mulch increases survival and growth of a Jeffery pine plantation. Tree Plant. Notes 1969, 19, 7-10.

42. Bowersox, T.W.; Ward, W.W. Black polyethylene mulch-An alternative to mechanical cultivation for establishing hybrid poplars. Tree Plant. Notes 1969, 21, 21-24.

43. Grossnickle, S.C. Ecophysiology of Nothern Spruce Species, The Performance of Planted Seedling; NRKC Research press: Ottawa, ON, Canada, 2000; pp. 266-269.

44. Friend, A.L.; Scarascia-Mugnozza, G.; Isebrands, J.G.; Heilman, P.E. Quantification of two-year-old hybrid poplar root systems: Morphology, biomass, and 14C distribution. Tree Physiol. 1991, 8, 109-119.

(C) 2015 by the authors; licensee MDPI, Basel, Switzerland. This article is an open access article distributed under the terms and conditions of the Creative Commons Attribution license (http://creativecommons.org/licenses/by/4.0/). 